T.J. Coonan MDCM FRCP(C),

C.E. Hope $\mathrm{MB}$ CH B FFARCS FRCP(C),

W.J. Howes MD FRCS(C),

R.O. Holness BSC MB BS FRCS(C),

E.L. MacInnis DDS FRCD(C)

\title{
Ankylosis of the temporo-mandibular joint after temporal craniotomy: a cause of difficult intubation
}

It is not generally appreciated that surgery in the region of the temporal fossa commonly produces, within a few weeks, a contracture of the temporalis muscle with "pseudo" ankylosis of the jaw. This usually, but not always, resolves within six months. The aetiological possibilities include, singly or in combination:

1. Postincisional scar formation within the muscle.

2. A Volkman's contracture due to devascularization of the muscle.

3. Organization of haematoma.

It is recommended that active and passive jaw exercises be started early after surgery in the temporal fossa and that such postcraniectomy patients be carefully assessed for jaw ankylosis prior to undertaking anaesthesia.

\section{Key words}

INTUBATION, ENDOTRACHEAL: difficult; SURGERY: craniotomy; COMPLICATIONS: joint ankylosis.

Trismus is common after surgery of the temporal fossa and usually resolves within three to four weeks as speech and mastication are resumed. This trismus is not due merely to muscle spasm but is rather a true contracture which is refractory to muscle relaxants and is potentially an impediment to laryngoscopy and intubation.

\section{Case report}

A 66-year-old woman presented for superficial temporal to middle cerebral artery bypass prior to left

From the Departments of Anaesthesia, Neurosurgery and Oral Surgery, Dahousie University.

Address correspondence to: Dr. T.J. Coonan, Department of Anaesthesia, Victoria General Hospital, Halifax, Nova Scotia, B3H 2 Y9. internal carotid clamping. Seven weeks earlier a left temporal craniotomy had been performed for exploration of a giant intracavernous and suprasellar aneurysm which was found not to be amenable to direct surgical management. No airway difficulties had been encountered during the anaesthetic.

On preoperative examination, the patient was confused and unco-operative, and a severe temporomandibular ankylosis was missed.

Anaesthesia was induced with thiopentone, droperidol and fentanyl. Muscle paralysis was induced with pancuronium $0.1 \mu \mathrm{g} \cdot \mathrm{kg}^{-1}$ and confirmed with ulnar nerve stimulation. On attempting intubation, it was found that the mouth could not be opened more than two centimeters. Laryngoscopy was impossible but the airway was easily maintained. Intubation by fiberoptic laryngoscopy was attempted but failed due to presence of copious oral secretions. It was elected to proceed no further and anaesthesia was abandoned.

After the patient had recovered completely a detailed clinical assessment and review of skull and neck $x$-rays was undertaken. It was clear that there was a severe mechanical limitation to opening the mouth and that the patient had difficulty even eating or drinking. In view of the total clinical situation, and the inability of the patient to co-operate, no attempt was made to carry out further definitive radiological or electromyographical studies.

The patient returned to the operating room one week later. She was unco-operative and refused to lie supine, and since she still had the large internal carotid artery aneurysm at risk of rupturing, it was considered that either tracheostomy or tracheal intubation under local analgesia would be dangerous. In that there had been no difficulty with airway management using manual ventilation and a face mask one 
week earlier, it was elected to perform a tracheostomy under general anaesthesia. The tracheostomy, superficial temporal to middle cerebral artery bypass, and the application of a Selverstone clamp to the left internal carotid artery was completed successfully. The aneurysm regressed in size and there was eventual remission of both the ophthalmoplegia and confusion.

Over a 12-month period the ankylosis has improved in that the patient can eat a normal diet and does not feel the need for surgical treatment. A limitation of jaw opening, which will make tracheal intubation difficult, does however still exist.

\section{Discussion}

The temporalis muscle arises from the whole of the temporal fossa, the zygomatic bone, and from the deep surface of the temporalis fascia. It is inserted into the coronoid process and anterior border of the ramus of the mandible nearly as far as the last molar tooth. Its action is to elevate the mandible. 'The functional anatomy of the temporo-mandibular joint (TMJ) has been reviewed. ${ }^{2,3}$

True and false ankylosis of the TMJ are distinguished according to whether the process is intraarticular or extra-articular. Bums, chronic infection, myositis ossificians, radiotherapy, trauma, malformation of the coronoid process, primary myopathy and foreign bodies have been recognized as potential causes of TMJ false ankylosis. ${ }^{4-6}$ Unremitting false ankylosis after surgery in the region of the temporal fossa has been described in the oral surgical ${ }^{4,7-9}$ and neurosurgical literature ${ }^{10}$ but not to our knowledge in the anaesthesia literature. While this complication commonly occurs following this particular approach to craniotomy, the exact incidence is not known.

There are several possible reasons for $\mathrm{T}-\mathrm{M}$ joint ankylosis after incisions in the temporal fossa. Skeletal muscle when injured does not regenerate. ${ }^{10}$ Instead a connective tissue scar forms with a tendency to contract as in all scar tissue. With time, in the active muscle, the muscle fibers will stretch to compensate for the area of contracted fibrous tissue. This could account for the temporary nature of the $\mathrm{T}-\mathrm{M}$ joint limitation seen in the majority of postoperative fronto-temporal craniotomy patients.

An alternative explanation could be a Volkman's ischaemic process following compromise of the blood supply of the temporalis muscle by the surgical incision which involves electrocautery incision of the temporalis muscle, fascia and periosteum, and stripping of the temporalis muscle and periosteum from the temporal fossa with possible sacrifice of the main branches of the deep temporal artery. ${ }^{10}$ Volkman's ischaemia is progressive with time; however, elongation and hypertrophy of normal remaining muscle might be expected to compensate for the area of contracture.

A third possible mechanism might be the organization of blood which has tracked down between the temporalis muscle and fascia in the temporal fossa. ${ }^{4}$ The resultant fibrosis and contracture could cause a restriction of movement of the temporalis muscle and eventual disuse atrophy of that muscle.

Electromyography in patients with postsurgical false ankylosis shows increased masseter activity and pronounced bilateral temporal activity, ${ }^{9}$ but this would seem to be a non-specific response. These patients frequently complain of headache. ${ }^{6}$

The false ankylosis will usually improve with time. The rare case of prolonged ankylosis probably occurs in the patient who does not actively use his temporalis muscle early, or in whom the temporalis muscle has been rendered ischaemic to an unusual degree. It is possible that if the contracture is sufficiently longstanding, ossification will occur in the fibrotic muscle.

Rarely patients with this type of false ankylosis require surgical release of longstanding incapacitating ankylosis. This generally involves coronoidectomy and detachment of the temporalis muscle fibres from the mandible. Surgical management should rarely be required however and an expectant conservative approach with physiotherapy is generally advisable for at least a six-month period. An early return to full diet and the utilization of both passive tongue blade stretching exercises and active mouth opening exercises against resistance are considered helpful. ${ }^{10}$ Moist heat reduces the muscle pain during the active exercises.

Patients who have had surgery in the region of the temporal fossa require a meticulous assessment of TMJ function prior to anaesthesia. ${ }^{21}$ Maximum mandibular opening should be in the range of $40 \mathrm{~mm}$ (two fingerbreadths). The TMJ is assessed by placing the middle finger of each hand just inferior and posterior to the ear lobe while at the same time the index finger is positioned just anterior to the tragus. When the patient opens his mouth, the 
initial rotational and secondary sliding movement of the condylar head should be felt. False ankylosis can be differentiated from true ankylosis because, in the former condition, although the jaw cannot open, the capacity for forward sliding is maintained. ${ }^{12}$ In the event of ankylosis, full evaluation should be undertaken to exclude causes such as infection or foreign body. Radiological evaluation of the zygoma and mandible, as well as panoramic views of the TMJ in the closed and attempted open positions should be made. More detailed views of local anatomy may be obtained with polytomographs. Waters view radiographs and submental vertex views will show the size and morphology of the coronoid processes. ${ }^{5}$

The usual approaches to the non-accessible airway include oro- or naso-tracheal intubation (fibreoptic or blind), or tracheostomy, under local analgesia in the awake patient. In certain circumstances, and particularly where definitive treatment of the false ankylosis is required, an alternative option is coronoidotomy which can be performed utilizing local analgesia and a neuroleptic IV technique.

\section{Acknowledgement}

The authors wish to thank Polly Moores for secretarial help.

\section{References}

1 Williams PL, Warwich R, eds. Gray's Anatomy. 36th ed. Edinburgh: Churchill Livingstone 1980.

2 Block $C, B$ rechner $V L$. Unusual problems in airway management. II. The influence of the temporomandibular joint, the mandible, and associated structures on endotracheal intubation. Anesth Analg 1971; 50: 114-23.

3 Dolwich MF. The temporomandibular joint: nor$\mathrm{mal}$ and abnormal anatomy. $I n$ : Internal Derangements of the Temporomandibular Joint. Helms CA, Katzberg RW, Dolwich MF eds. San Francisco: Radiology Research and Education Foundation, 1983.

4 Summers $L$. False ankylosis of the temporo-mandibular joint following craniotomy. Br J Oral Surg 1980; 18: 138-40.

5 Guralnick WC, Kaban LB. Surgical treatment of mandibular hypomobility. J Oral Surg 1976; 34 : 343-8.

6 Powers $J M$, Young GF, Bass EB, Reed FE. Atypical nemaline myopathy with temporomandibular ankyloses. Neurology 1980; 30: 971-5.
7 Khosla VM. Pseudoankylosis of mandible produced by temporal muscle fibrosis: report of case. J Oral Surg 1970; 28: 521-2.

8 Kwapis BW, Dyer $M H$. Pseudoankylosis following a temporoparietal craniotomy and its surgical correction, J Oral Surg 1974; 32: 912 -4.

9 Saunders B, Thorpe W, Kallal R. Pseudoankylosis of the mandible secondary to transcoronal neurosurgical procedure. J Oral Surg 1974; 32: 909-11.

10 Hendler BH, Kreger TM, Goldman HW. Fibrous ankylosis of the mandible following frontotemporal craniotomy. J Neurosurg 1981; 55: 836-7.

11 Yasargil MG, Fox JL, Ray $M W$. The operative approach to aneurysms of the anterior communicating artery. In: Krayenbuhl $\mathrm{H}$, ed. Advances and technical standards in neurosurgery. New York/Wien: Springer-Verlag, 1975; 2: 113-70.

12 Kazanjian $V H$. Ankylosis of the temporomandibular joint. Surg Gynecol Obst 1938; 67: 333-48.

\section{Résume}

Il n'est généralement pas reconnu qu' une chirurgie dans la région de la fosse temporale peut produire souvent, en quelques semaines, une contraction du muscle temporal avec une "pseudo" ankylose de la mâchoire. Souvent, mais pas toujours, celle-ci se dissipe en-dedans de six mois. Les possibilités étiologiques incluent un ou une combinaison des facteurs suivants:

1. La formation de cicatrice musculaire post-incisionnelle.

2. Une contracture de Volkman par dévascularisation du muscle

3. L'organisation d'un hématome.

Il est recommandé de commencer aussizôt que possible après la chirurgie sur la fosse temporale des exercices passifs et acrifs. Les patients post craniectomie doivent être soigneusement évalués pour l'ankylose de la mâchoire avant d'entreprendre l'anesthésie. 